\title{
Dependence of Canine-Guided and Group Guided Occlusion on Angle's Classification and Gender
}

\author{
Kashif Aslam ${ }^{1}$ \\ Rizwan Nadim ${ }^{2}$ \\ Sofia Ali Syed $^{3}$
}

\author{
BDS, MSc \\ BDS, MPH \\ BDS, M.Phil
}

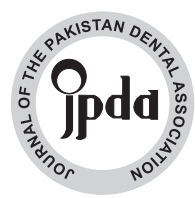

OBJECTIVE: The purpose of this study was to find out the dependence of canine guided and group guided occlusion on Angles classification and gender.

METHODOLOGY: A cross sectional study was conducted Altamash Institute of Dental Medicine (AIDM) and Dow Dental College (DDC) from 2012 to 2014. Six hundred (600) participants were selected using non randomized purposive sampling technique. Visual observation and articulating paper were used to assess canine guided or group guided occlusion in relation to Angles classification and gender. Data was analyzed by using software SPSS 16.0. Pearson chi square was applied to observe the dependence of canine guided and group guided occlusion on Angles classification and gender.

RESULT: Group guided occlusion was more prevalent in Angles Class 3 and canine guidance was more established in both genders. However, results were statistically insignificant ( $p>0.05)$.

CONCLUSION: Canine guided and group guided occlusion were independent of Angles classification and gender. KEY WORDS: canine and group occlusion, balanced occlusion, prevalence, orthodontics, prosthetics, Angle's classification.

HOW TO CITE: Aslam K, Nadim R, Syed SA. Dependence of canine-guided and group guided occlusion on angle's classification and gender. J Pak Dent Assoc 2018;27(2):67-70.

DOI: https://doi.org/10.25301/JPDA.272.67

Received: 27 October, 2017, Accepted: 22 March, 2018

\section{INTRODUCTION}

B iological variations include genetic variation that affects dentition in general and environmental variation that affects specific tooth shape, size and function. Establishing or providing occlusion is the characteristic of dentistry. The synchronization of occlusion during mandibular movement is maintained by the posterior teeth that should not come in contact with opposite teeth. The posterior teeth depend on anterior teeth for their stability; therefore anterior guidance is of considerable importance. Anterior guidance is divided into canine guided, group guided and balanced occlusal scheme. ${ }^{1}$

In canine guided occlusion, the overlap of maxillary and mandibular canines results in disengagement of maxillary and mandibular posterior teeth during excursive movement of mandible whereas group guided occlusion results in multiple contacts of maxillary and mandibular teeth on working side during lateral movement of mandible. Although there is no evidence to suggest which type of occlusion

1. Associate Professor, Department of Prosthodontics, Dow Dental College, D.U.H.S.

2. PhD Scholar, Department of Community Dentistry, University of Wolverhampton.

3. Assistant Professor, Department of Oral pathology, Dow Dental College, D.U.H.S.

Corresponding author: "Dr. Kashif Aslam" < taimoor.links@ gmail.com > should be taken into account yet canine guided is preferred over group function. Canine guided is not only easy in designing and manufacturing but it also involves less muscular activity and less forces on teeth compared to group function. ${ }^{2}$ Various studies reported the prevalence of canine guided or group guidance but the dependence of canine guided and group guidance occlusion in Angle's classification is sparse. ${ }^{3,4}$ Therefore, the purpose of the study was to find out the dependence of canine guided and group guided occlusion among Angle's classification and gender.

\section{METHODOLOGY}

The study was conducted at Altamash Institute of Dental Medicine (AIDM) and Dow Dental College from 2012 to 2014. Six hundred participants were selected using non randomized, purposive sampling technique according to Angle's classification. Individuals containing at least 28 permanent teeth were selected irrespective of age. Individuals present in the study were either patients, patient's attendants, doctors, and lower staff as the target population. Individuals undergoing orthodontic treatment, having bridges, undergone occlusal splint therapy and extractions were not involved due to the potential of alteration in original occlusion. To 
observe canine guidance or group guidance, articulating paper (Henry Schein, New York, U.S.A) of 40 micron meter was placed between upper and lower teeth during normal chewing pattern of individuals. Visual observation was done under dental chair light ( Dawn plus, Pakistan) with cheeks fully retracted with mouth mirror (United, Pakistan) to obtain a lateral view of Angles Class 1, Class 2 division 1, Class 2 division 2, and Class 3 and articulating marks that were obtained during normal chewing pattern. Verbal consent was taken from head of the department and participants. Data was analyzed by using software SPSS 16.0. Pearson chi square was applied to observe the dependence of canine guided and group guided occlusion on Angles classification and gender

\section{RESULTS}

In this study 600 individuals were selected with age ranged from 15-50 year. The mean age was 26.6. Out of 600 individuals 375 (62.5\%) were females and 225 $(37.5 \%)$ were males. The female to male ratio was 1.6:1. (Figure 1).

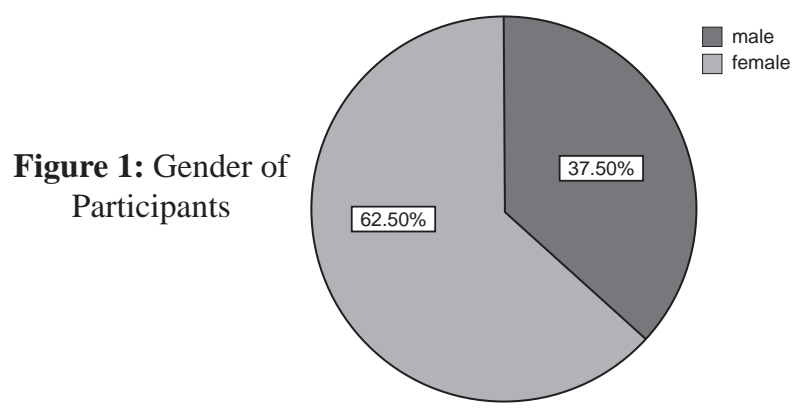

Among 600 participants we observed Angle's Class I in 376 (62.6\%), Class II div 1 in 130 (21.7\%), Class 2 div 2 in 33 $(5.5 \%)$ and Class III in $61(10.1 \%)$. Canine guided and group guided were seen in 332(55.3\%) and 268(44.7\%) participants respectively (Table 1$)$.

Out of $376(62.6 \%)$ cases of class I, 184 (49.09\%) had canine guided and $192(51.06 \%)$ showed group guided

Table 1: Demographic characteristic and prevalence of particular classes and guided occlusions in studied subjects

\begin{tabular}{|l|l|l|}
\hline Characteristics & Frequency & Percentage \\
\hline Age & & \\
\hline Mean \pm SD & $26.66 \pm 7.98$ & \\
\hline Gender & & \\
\hline Male & 225 & 37.5 \\
\hline Female & 375 & 62.5 \\
\hline Class 1 & 376 & 62.6 \\
\hline Class 2 div 1 & 130 & 21.7 \\
\hline Class 2 div 2 & 33 & 5.5 \\
\hline Class 3 & 61 & 10.1 \\
\hline Canine guided & 332 & 55.3 \\
\hline Group guided & 268 & 44.7 \\
\hline
\end{tabular}

Table 2: Frequency of canine and group guided occlusion in Angles classification

\begin{tabular}{|l|l|l|l|l|l|}
\hline & \multicolumn{2}{|l|}{$\begin{array}{l}\text { Canine guided } \\
\text { occlusion }\end{array}$} & \multicolumn{2}{l|}{$\begin{array}{l}\text { Group guided } \\
\text { occlusion }\end{array}$} & \\
\hline & Present & Percentage & Present & Percentage & Total \\
\hline Class 1 & 184 & 49.09 & 192 & 51.06 & 376 \\
\hline $\begin{array}{l}\text { Class 2 } \\
\text { div 1 }\end{array}$ & 97 & 29.2 & 33 & 12.3 & 130 \\
\hline $\begin{array}{l}\text { Class 2 } \\
\text { div 2 }\end{array}$ & 25 & 7.5 & 8 & 3 & 33 \\
\hline Class 3 & 26 & 42.6 & 35 & 57.37 & 61 \\
\hline
\end{tabular}

Table 3: Frequency distribution of Canine and Group guided occlusion with respect to gender in study participants

\begin{tabular}{|l|l|l|l|l|l|}
\hline $\begin{array}{l}\text { Gender } \\
\text { of the } \\
\text { participa } \\
\text { nt }\end{array}$ & $\begin{array}{l}\text { Canine } \\
\text { guided } \\
\text { occlusion }\end{array}$ & Percentage & $\begin{array}{l}\text { Group } \\
\text { guided } \\
\text { occlusion }\end{array}$ & Percentage & Total \\
\hline Male & 126 & $56 \%$ & 99 & $44 \%$ & 225 \\
\hline Female & 206 & $54.93 \%$ & 169 & $45 \%$ & 375 \\
\hline$P>0.05$
\end{tabular}

occlusion. Among 130 (21.7\%) cases of Class II div 1, 97 (29.2\%) had canine guided and $33(12.3 \%)$ had group guided occlusion. In 33 cases of class 2 div 2, 25 (7.5\%) had canine guided and $8(3 \%)$ were group guided. However in $61(10.1 \%)$ participants of Class III, 26(42.6\%) and 35(57.37\%) showed canine guided and group guided occlusion respectively (Table 2). Canine guided and group guided occlusion were independent of Angles malocclusion ( $p>0.05)$ Out of 225 males, 126 exhibit canine guided while 99 showed group guided occlusion. In 375 females, 206 had canine guided while the remaining 169 showed group guidance (Table 3). Canine guided and group guided was also statistically insignificant in gender ( $p>0.05)$.

\section{DISCUSSION}

In many studies occlusal contacts in lateral position are recorded in an edge to edge position of canines which is about $3 \mathrm{~mm}$ from maximum intercuspation. This position is rarely used nowadays and recent studies have a range of 1-3 mm and $0.5 \mathrm{~mm} .{ }^{4}$ In our study, instead of using any range of motion, the participants were asked to chew as they do in their normal routine and then contacts were observed on teeth marked by articulating paper. Articulating paper of 40 micron meter was used because of ease of availability which is in accordance with the previous study. ${ }^{5}$ However some studies proposed the use of shimstock. ${ }^{6,7}$

We observed 376 patients with Angle's class I in which $192(51.06 \%)$ exhibited group guided and $184(49.09 \%)$ were found to be canine guided which is similar to the 
previous studies. ${ }^{8,9}$ By contrast Abduo et al observed prevalence of canine guided occlusion. ${ }^{3}$

A study ${ }^{10}$ reported 1200 participants from North America less than 25 years of age and found that majority had unilateral or bilateral canine guided occlusion. They also correlated that canine guided occlusion was associated with decreasing order in Angle class II, I and III occlusion. Abduo et $\mathrm{al}^{3}$ also found predominance of canine guidance in class 2 while group function in class 3 as seen in our study. Other studies by Al-Hiyasat ${ }^{11}$ and Al-Nimri ${ }^{1}$ showed similar results. In our study, group guided occlusion was more frequently found in Angle's class III (57\%), then class I $(51 \%)$ and least in class II (25\%) which is comparable to other studies. ${ }^{1}$

Asawaworarit ${ }^{12}$ reported group guidance as predominant occlusal pattern in Thai individuals. Similarly another study reported both group and canine. ${ }^{13}$

Among functional occlusion schemes, no single type is predominant. For example, However, Woda et $\mathrm{al}^{14}$ suggested balancing contacts compared to canine or group function occlusal relationships. Rinchuse et al reported loss of canine guidance in individuals who eat coarse and abrasive food. ${ }^{15}$ Ogawa et $\mathrm{al}^{4}$ also found no difference in the occurrence of canine and group guidance in relation to genders which is in accordance to our study. While canine guidance decreases with age, it is considered as the most suitable occlusal scheme in young patients undergoing orthodontic and prosthetic treatment. ${ }^{16,17}$

During occlusal rehabilitation in restorative dentistry, where it is likely to use specific occlusal pattern, various epidemiological and physiological studies have been observed to establish a rational based on choosing group guided and canine guided occlusion. ${ }^{12,18}$ A study showed a high frequency of tooth contacts on non-working sides; however, multiple tooth contacts on either working sides were also reported. ${ }^{19}$ Various studies showed occlusal relationship with tooth contacts on non-working side. ${ }^{20}$

\section{Limitation}

Canine guided and group guided occlusion was observed intraorally which could have been counter checked by mounting them on adjustable articulators with face bow records.

\section{CONCLUSION}

Canine guided and group guided occlusion were independent of Angles classification and gender.

\section{CONFLICT OF INTEREST}

None declared.

\section{REFERENCES}

1. Al-Nimri KS, Bataineh AB, Abo-Farha S. Functional occlusal patterns and their relationship to static occlusion. Angle Orthod. 2010;80(1):65-71.

https://doi.org/10.2319/021209-98.1

2. Sapkota B, Gupta A. Pattern of occlusal contacts in lateral excursions (canine protection or group function). Kathmandu Univ Med J. 2014;45(1):43-7.

3. Abduo J, Tennant M, McGeachie J. Lateral occlusion schemes in natural and minimally restored permanent dentition: a systematic review. J Oral Rehabil. 2013;40(10):788-802.

https://doi.org/10.1111/joor.12095

4. Song J-H, Joo S-J, Lee H-S, Kang D-W, Lee G-J. An occlusal contact analysis of lateral mandibular movement using T-Scan system. J Korean Acad Prosthodont. 2015;53(2):128-37.

https://doi.org/10.4047/jkap.2015.53.2.128

5. Panek H, Matthews-Brzozowska T, Nowakowska D, Panek B, Bielicki G, Makacewicz S, et al. Dynamic occlusions in natural permanent dentition. Quintessence Int. 2008;39(4). 6. Hulley SB, Cummings SR, Browner WS, Grady DG, Newman TB. Designing clinical research: Lippincott Williams \& Wilkins; 2013.

7. Gupta A, Shenoy VK, Shetty TB, Rodrigues SJ. Evaluation of pattern of occlusal contacts in lateral excursion using articulating paper and shim stock: An in vivo study. J Interdiscip Dent. 2013;3(2):109.

https://doi.org/10.4103/2229-5194.126874

8. Touzi S, Chakroun M, Abderrahmen SB, Kallala R, Hadyaoui D, Harzallah B, et al. The Relationship between Static and Dynamic Occlusion in Natural Permanent Dentition: A Descriptive Epidemiological Study.Int J Health Sci Res. 2015;5(12):209-13.

9. Francová K, Eber M, Zapletalová J. Functional occlusal patterns during lateral excursions in young adults. J Prosthet Dent. 2015;113(6):571-7.

https://doi.org/10.1016/j.prosdent.2014.12.004

10. Scaife RR, Holt JE. Natural occurrence of cuspid guidance. J Prosthet Dent. 1969;22(2):225-9.

https://doi.org/10.1016/0022-3913(69)90249-2

11. Al-Hiyasat A, Abu-Alhaija E. The relationship between static and dynamic occlusion in 14-17-year-old school children.J Oral Rehab. 2004;31(7):628-33.

https://doi.org/10.1111/j.1365-2842.2004.01283.x

12. Asawaworarit N, Mitrirattanakul S. Occlusal scheme in a group of Thais. J Adv Prosthodont. 2011;3(3):132-5. https://doi.org/10.4047/jap.2011.3.3.132

13. Miralles R. Canine-guide Occlusion and Group Function Occlusion are Equally Acceptable When Restoring the 
Dentition. J Evid Based Dent Pract. 2016;16(1):41-3. https://doi.org/10.1016/j.jebdp.2016.01.029

14. Woda A, Vigneron P, Kay D. Nonfunctional and functional occlusal contacts: a review of the literature. J Prosthet Dent. 1979;42(3):335-41.

https://doi.org/10.1016/0022-3913(79)90226-9

15 . Rinchuse DJ, Kandasamy S, Sciote J. A contemporary and evidence-based view of canine protected occlusion. Am J Orthod Dentofacial Orthop. 2007;132(1):90-102. https://doi.org/10.1016/j.ajodo.2006.04.026

16. Pasricha N, Sidana V, Bhasin S, Makkar M. Canine protected occlusion. Indian J Oral Sci. 2012;3(1):13. https://doi.org/10.4103/0976-6944.101670

17. Al-Nassar DB, Al-Hashimi HA. Orthodontic considerations of functional occlusion in Class I normal occlusion. J Baghdad Coll Dent. 2015;27(3):130-9. https://doi.org/10.12816/0015047

18. Funding So. Review analysis and evaluation canineguide occlusion and group function occlusion are equally acceptable when restoring the dentition article title and bibliographic information. J Prosthet Dent. 2015;114:193204.

19. Kaidonis J, Ranjitkar S, Lekkas D, Brook A, Townsend G. Functional dental occlusion: an anthropological perspective and implications for practice. Aust Dent J. 2014;59(s1):16273.

https://doi.org/10.1111/adj.12133

20. Parnia F, Fard EM, Sadr K, Motiagheny N. Pattern of occlusal contacts in eccentric mandibular positions in dental students. J Dent Res Dent Clin Dent Prospects. 2008;2(3):85. 